\title{
Assessing risks and benefits of floral supplements in conservation biological control
}

\author{
Karin Winkler • Felix L. Wäckers • \\ Aad J. Termorshuizen · Joop C. van Lenteren
}

Received: 10 January 2010/Accepted: 2 June 2010/Published online: 20 June 2010

(C) The Author(s) 2010. This article is published with open access at Springerlink.com

\begin{abstract}
The use of flowering field margins is often proposed as a method to support biological control in agro-ecosystems. In addition to beneficial insects, many herbivores depend on floral food as well. The indiscriminate use of flowering species in field margins can therefore lead to higher pest numbers. Based on results from field observations and laboratory experiments we assessed risks as well as benefits associated with the provision of nectar plants in field margins, using Brussels sprouts as a model system. Results show that Brussels sprouts bordered by nectar plants suitable for the cabbage white Pieris rapae L., suffered higher infestation levels by this herbivore. In contrast, nectar plants providing accessible nectar for the diamondback moth Plutella xylostella L., did not raise densities
\end{abstract}

Handling Editor: Torsten Meiners.

K. Winkler $(\bowtie)$. A. J. Termorshuizen .

J. C. van Lenteren

Wageningen University, Wageningen, The Netherlands e-mail: k.winkler1@kpnplanet.nl

A. J. Termorshuizen

e-mail: Aad.Termorshuizen@wur.nl

J. C. van Lenteren

e-mail: Joop.vanLenteren@wur.nl

F. L. Wäckers

Centre for Sustainable Agriculture, Lancaster University,

Lancaster, UK

e-mail: f.wackers@lancaster.ac.uk of P. xylostella larvae in the Brassica crop. Margins with Anethum graveolens L., selected on the basis of its suitability as nectar plant for parasitoids, significantly increased the number of adult Diadegma semiclausum Hellén in the crop. This didn't translate into enhanced parasitism rates, as parasitism of $P$. xylostella by D. semiclausum exceeded $65 \%$ in all treatments, irrespective of the plants in the field margin. Our findings emphasize the importance of taking a multitrophic approach when choosing flowering field margin plants for biocontrol or other ecosystem services.

Keywords Nectar Pieris rapae .

Plutella xylostella . Diadegma semiclausum .

Herbivore · Parasitoid · Multitrophic interactions . Indirect trophic interactions - Biological control . Ecosystem services

\section{Introduction}

Diversification of agro-ecosystems is often advocated as a tool to provide essential nectar and pollen resources to parasitoids and predators and thereby enhance the efficacy of biological pest control (Gurr et al. 2005; Heimpel and Jervis 2005). Under laboratory conditions, nectar supply often has a great impact on longevity (Zoebelein 1955; van Lenteren et al. 1987; Idris and Grafius 1995; Wäckers 2001), fecundity (Idris and Grafius 1995; McEwen and Liber 1995; Baggen and Gurr 1998; Winkler et al. 2006) 
and activity of parasitic wasps (Takasu and Lewis 1994; Wäckers 1994). Under field conditions, the presence of flowers may (locally) increase the abundance of beneficial insects (White et al. 1995; Patt et al. 1997; Bianchi and Wäckers 2008) and rates of parasitism (Stephens et al. 1998; Lee and Heimpel 2008).

While conservation biological control programs have largely focused on nectar and pollen use by beneficial insects, the fact that many herbivores also feed on these floral resources has received relatively little attention (McEwen and Liber 1995; Baggen and Gurr 1998; Romeis et al. 2005; Wäckers et al. 2007). For a number of natural systems it has been shown that oviposition by herbivores can be increased in the vicinity of adult food plants (Grossmueller and Lederhouse 1987; Murphy 1983; Murphy et al. 1984; Karban 1997). Also in agricultural systems habitat diversification may result in elevated pest numbers (Latheef and Irwin 1979; Andow 1991; Zhao et al. 1992; Romeis et al. 2005; Bianchi et al. 2006).

Whereas nectar and pollen feeding has often been implicated as the underlying mechanism for these adverse effects, the experiments were usually not laid out to establish causality. Instead, experiments frequently addressed other questions like the impact of biodiversity (Andow 1991; Bianchi et al. 2006) or repellence by companion plants (Latheef and Irwin 1979). Zhao et al. (1992) reported that Pieris rapae L. (Lepidoptera: Pieridae) eggs and larvae were more abundant in crops interplanted with a mix of nectar plants, as compared to monocultures, but did not underpin this with statistics. Luna (personal comm.) found a higher abundance of $P$. rapae larvae in broccoli due to Fagopyrum esculentum Moench (Caryophyllales: Polygonaceae) borders, while Lee and Heimpel (2005) found no increase in $P$. rapae densities in cabbage adjacent to $F$. esculentum. In order to single out nectar feeding as a potential mechanism underlying increased herbivore levels, Winkler et al. (2009b) studied the impact of flowering margins on herbivore and parasitoid carbohydrate reserves. Using HPLC sugar analyses, it was shown that the average overall sugar content of Plutella xylostella L. (Lepidoptera: Plutellidae) and Diadegma semiclausum Hellén (Hymenoptera: Ichneumonidae) collected in fields bordered by Anethum graveolens L. (Apiales: Apiaceae) and
Lobularia maritima (L.) Desv. (Brassicales: Brassicaceae) was significantly higher than those of individuals collected from Lolium perenne-bordered control plots.

Here we study whether floral resources affect herbivore and parasitoid spatial dynamics with an experimental design based on our previous work in which we established visitation rates and survival of Brassica herbivores and/or their natural enemies on a range of flowering herbs. Field observations showed clear differences in flower visitation (Winkler et al. 2005a) and laboratory studies indicated that nectar plants are not equally suitable in providing accessible nectar and prolonging lifespan of cabbage herbivores and their parasitoids (Winkler et al. 2009a). These results were used to identify and test a parasitoid selective/herbivore selective scenario which is unique in allowing us to address both benefits of flowering vegetation to biological control agents as well as risks in enhancing pest pressure.

The "best-case scenario" of our study consisted of a Brussels sprout plot bordered by A. graveolens. This species provides accessible nectar for the parasitoids Cotesia glomerata L. (Hymenoptera: Braconidae) and D. semiclausum, while being unsuitable for the herbivore $P$. rapae. The "worst-case scenario" consisted of a Brussels sprout plot bordered by Centaurea jacea L. (Asterales: Asteraceae). This species is an attractive and suitable nectar source for $P$. rapae, while being unsuitable for the parasitoids. In addition, we also tested the plant species $F$. esculentum, which takes an intermediate position providing accessible nectar for both $P$. rapae and the parasitoids. All three plant species provide accessible nectar for $P$. xylostella, the host of $D$. semiclausum. As a control we used field margins with the grass Lolium perenne L. (Poales: Poacea), which does not provide nectar.

\section{Materials and methods}

Experimental setup

Small fields $(8 \times 10 \mathrm{~m}$ in size $)$ with Brussels sprouts (Brassica oleracea var. gemmiferra cv. Maximus) were established at two experimental locations, Wageningen Hoog (WH) in 2002 and Achterberg (AB) in 2002 and 2003. These locations are situated 
near Wageningen, The Netherlands. Brussels sprouts were transplanted as seedlings to the field in week 21 in 2002 and week 22 in 2003. Planting distance was $80 \mathrm{~cm}$ between the rows and $50 \mathrm{~cm}$ within the rows. The distance between the plots was $35 \mathrm{~m}$.

Along the two long sides of each Brussels sprout plot a $1 \mathrm{~m}$ wide field margin was established. Field margins contained one of the following plants: L. perenne (grass, control), C. jacea, A. graveolens, or $F$. esculentum (Table 1). Each treatment was replicated twice in each site. In 2002, C. jacea was sown in the greenhouse and planted into the field in week 18. L. perenne (week 20), A. graveolens (week 17 in $\mathrm{WH}$ and week 18 in $\mathrm{AB}$ ), and $F$. esculentum (week 20) were sown directly into the field. A. graveolens was resown in week 20 to ensure good establishment of the plant. This resulted in flowering periods as indicated in Fig. 1.

In $2003, L$. perenne and $F$. esculentum were sown directly into the field in week 20 . A graveolens was sown in the greenhouse and planted into the field in week 22. As $C$. jacea is a perennial plant it was not replanted in the second year.

Plots and field margins were hand-weeded. The area between the plots was sown with L perenne, which was mown regularly during the season.

Monitoring adult insects

In 2003, we monitored naturally occurring adult $P$. rapae, $P$. xylostella and $D$. semiclausum both within the field margins and in row 3-4 and row 7-8 of each Brussels sprout plot. To count the easily visible $P$. rapae, we walked once around each field margin as well as through the Brussels sprout rows and recorded any visible adults. Small species like P. xylostella and D. semiclausum were sampled by sweep netting and checked for their sex. A standardized number of 12 sweeps was taken in each field margin as well as in row 3-4 and row 7-8 of each Brussels sprout plot. Sampling was done only in 2003 from week 29 until week 32 on sunny and dry days between 10:00 h and 15:00 h. Between 15 and 19 sweep net samples were taken per treatment.

Monitoring eggs and larvae

Brussels sprout plants were randomly monitored in a non-destructive way for $P$. rapae eggs and larvae and for $P$. xylostella larvae, pupae and cocoons (parasitized pupae). Monitoring was done on a weekly basis. In 2002, sampling took place from week 26 until week 36. Sampling started as soon as the first flower species started blooming and lasted until two weeks after the first flower species had terminated blooming. Sampling was done earlier in 2003, from week 24 until week 34 , due to exceptionally warm weather and the resulting faster development of the crop. With increasing plant size the number of monitored plants per field decreased. In 2002, 20 plants per field were sampled in week 26-28, 15 plants in week 29-30 and 10 plants in week $31-36$. In 2003, 15 plants per field were sampled in week $24-25$ and 10 plants in week 26-34.

Data evaluation

\section{Adult insects}

Per species we totalled the number of observed individuals for each plot and sample date to attain one figure for the field margins and one for the crop. To check for differences among treatments the data were totalled over sampling days and experimental locations. As data were not normally distributed, non-parametric statistics were used. When the

Table 1 Plant species used, their floral colour, nectar position and nectar provision for Pieris rapae and parasitoids

\begin{tabular}{lllll}
\hline Plant species (family) & Common name & Flower colour & Nectar position & $\begin{array}{l}\text { Provide nectar } \\
\text { for Pieris rapae/parasitoids }\end{array}$ \\
\hline Lolium perenne (Poaceae) & Perennial ryegrass & n.a. & No nectar & $-/-$ \\
Centaurea jacea (Asteraceae) & Brown knapweed & Purple & Hidden & $+/-$ \\
Anethum graveolens (Apiaceae) & Dill & Yellow & Exposed & $-/+$ \\
Fagopyrum esculentum (Polygonaceae) & Buckwheat & White & Exposed & $+/+$ \\
\hline
\end{tabular}

a Winkler et al. (2009a) 
Fig. 1 Flowering and sampling periods in the two experimental years

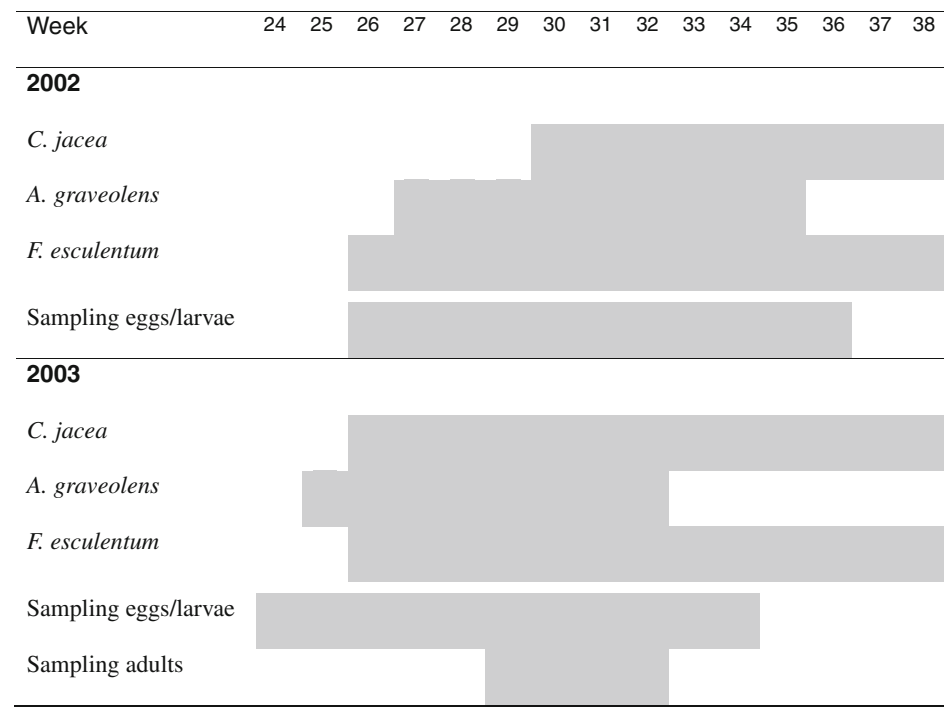

Kruskal-Wallis test indicated differences among treatments, the Mann-Whitney U test was used to compare the control treatment with each of the other treatments $(\alpha=0.05)$.

For each sampling event we calculated, which proportion of the total number of $P$. rapae adults was observed in the edge and in the field. These proportions of individuals observed in margins versus crop within the same plot were arcsine-root-transformed and subjected to a General Linear Model procedure (SAS statistical software, version 8e, Cary, NC, USA). Contrasts between treatments and control were tested for significance at $\alpha=0.05$.

\section{Eggs and larvae}

The average number of eggs and larvae per plant was calculated per field and week. For each field we subsequently calculated the cumulative average number of eggs and larvae over the whole experimental period (integral of the curve).

Each field margin treatment had six replicates when pooling together both locations and years. To check for the effect of treatment, data were analysed using a General Linear Model and consequently tested for contrasts of the treatments with the control (SAS $8 \mathrm{e}) \quad(\alpha=0.05)$. As $C$. jacea was poorly established in 2002 and primarily flowered in 2003, analysis was also done for 2003 data only.

We calculated the rate of parasitism by $D$. semiclausum as the proportion of pupae of P. xylostella containing a parasitoid cocoon out of the total number of pupae. This may underestimate the rate of parasitism, as cocoons, in which parasitoid larvae had not yet emerged and pupated, were counted as unparasitized. In addition, pre-pupal mortality of parasitoids was ignored. Average of parasitism per year and treatment were calculated from the rates of parasitism per plot and week.

\section{Results}

Presence of adult insects

We monitored visually a total of $54 P$. rapae individuals. Numbers of adult $P$. rapae in the margins and/or in the crop did not significantly differ between treatments. However, when the crop was bordered by C. jacea, the proportion of adults recorded in the crop and in the margin was significantly different from the proportions of adults observed in the control (Table 2, Fig. 2a). Numbers of $P$. xylostella were too low to allow statistics (4 females and 17 males).

For D. semiclausum, we collected a total of 136 females and 469 males by sweep netting. Significantly more D. semiclausum females and males were collected within the Brussels sprout fields bordered by A. graveolens as compared to the control. The number of D. semiclausum males was highest in fields bordered by $F$. esculentum. Numbers of D. semiclausum females and males observed in the field margins 
Table $2 P$-values obtained from statistical tests used for adult and offspring data

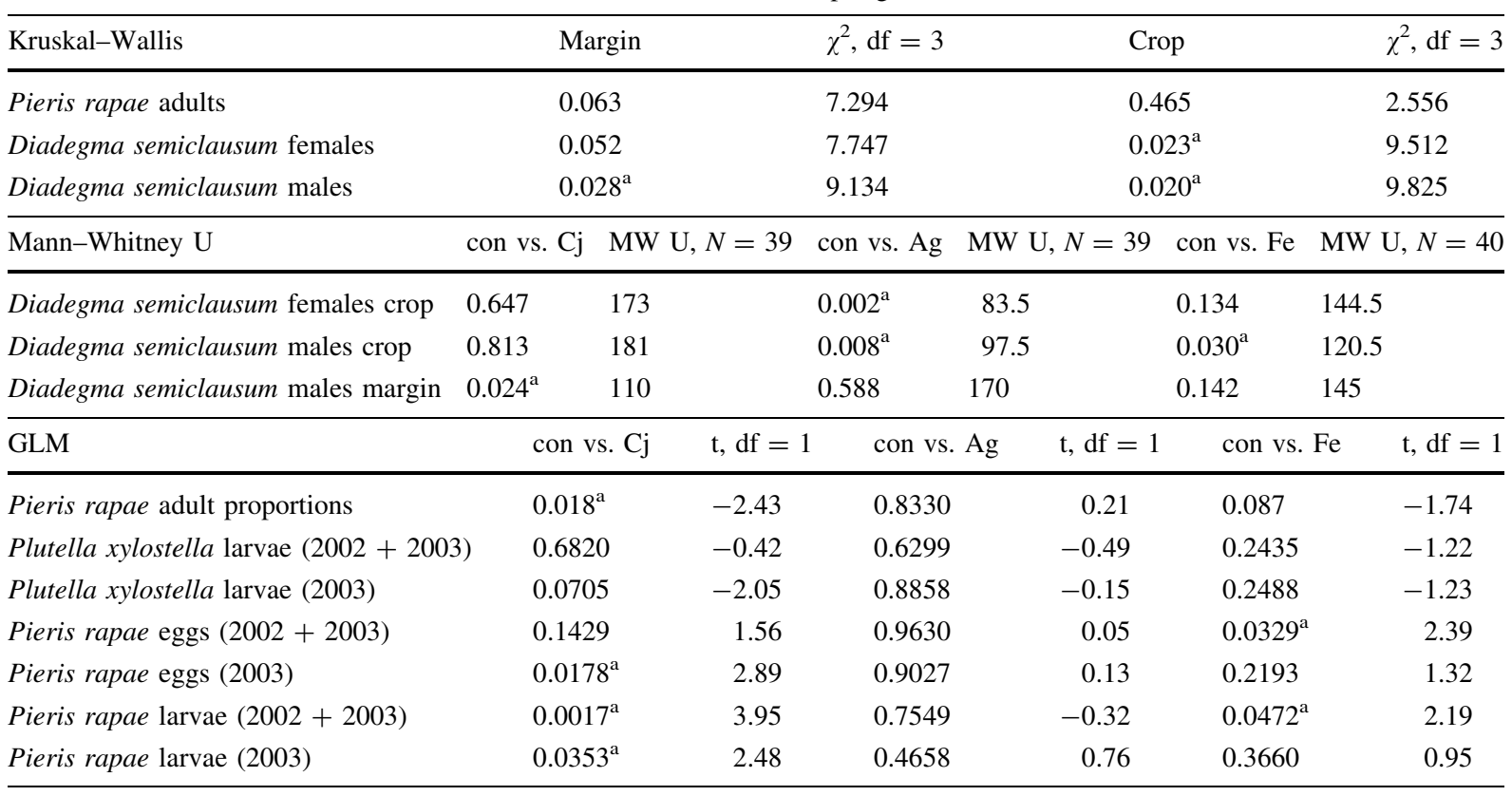

Treatments are indicated by con Control, $\mathrm{Cj}$ Centaurea jacea, Ag Anethum graveolens, Fe Fagopyrum esculentum

a Statistical differences at $\alpha=0.05$

were low (Table 2, Fig. 3b, c). In C. jacea margins we found significantly more male $D$. semiclausum than in Control margins. $P$-values for all statistical tests performed on adult data are listed in Table 2.

Presence of eggs and larvae

Overall, there were significantly higher numbers of $P$. rapae eggs per Brussels sprout plant in the field bordered by $F$. esculentum as compared to the control (Fig. 2b). In addition, the overall number of $P$. rapae larvae per Brussels sprout plant were higher in plots bordered by $C$. jacea and $F$. esculentum as compared to the control (Fig. 2b, c). When considering 2003 only, Brussels sprout plants bordered by $C$. jacea suffered higher $P$. rapae eggs and larvae loads as compared to the control.

We did not find significant differences in the number of $P$. xylostella larvae per Brussels sprout plant among treatments (Fig. 3a). The percentages parasitism of $P$. xylostella by the parasitoid $D$. semiclausum did not differ among treatments and reached on average $78 \pm 3 \%$ in the year 2002 and $67 \pm 3 \%$ in the year 2003 . For $P$-values of all comparisons made see Table 2.

\section{Discussion}

Our study demonstrates that floral resources can have a positive impact both on herbivore and parasitoid numbers in the field and shows unambiguously that this impact is insect- and flower-species specific. This finding underlines that the indiscriminate use of nectar plants in flowering field margins can enhance pest pressure and emphasizes the importance of floral composition in the optimization of ecosystem services.

The herbivore $P$. rapae showed higher egg and larval densities in fields bordered by $C$. jacea and F. esculentum, two flower species that had previously been shown to be suitable nectar sources for this herbivore (Winkler et al. 2009a). Moreover, adults of this species were recorded more frequently in plots bordered by $C$. jacea. The flower species that had been shown to be unsuitable as nectar source for $P$. rapae in our previous laboratory studies did not result in elevated pest numbers. The fact that $P$. rapae numbers are only enhanced by those plant species that had been selected on the basis of their suitability as nectar source for $P$. rapae supports the conclusion that nectar foraging and/or nectar feeding is the 

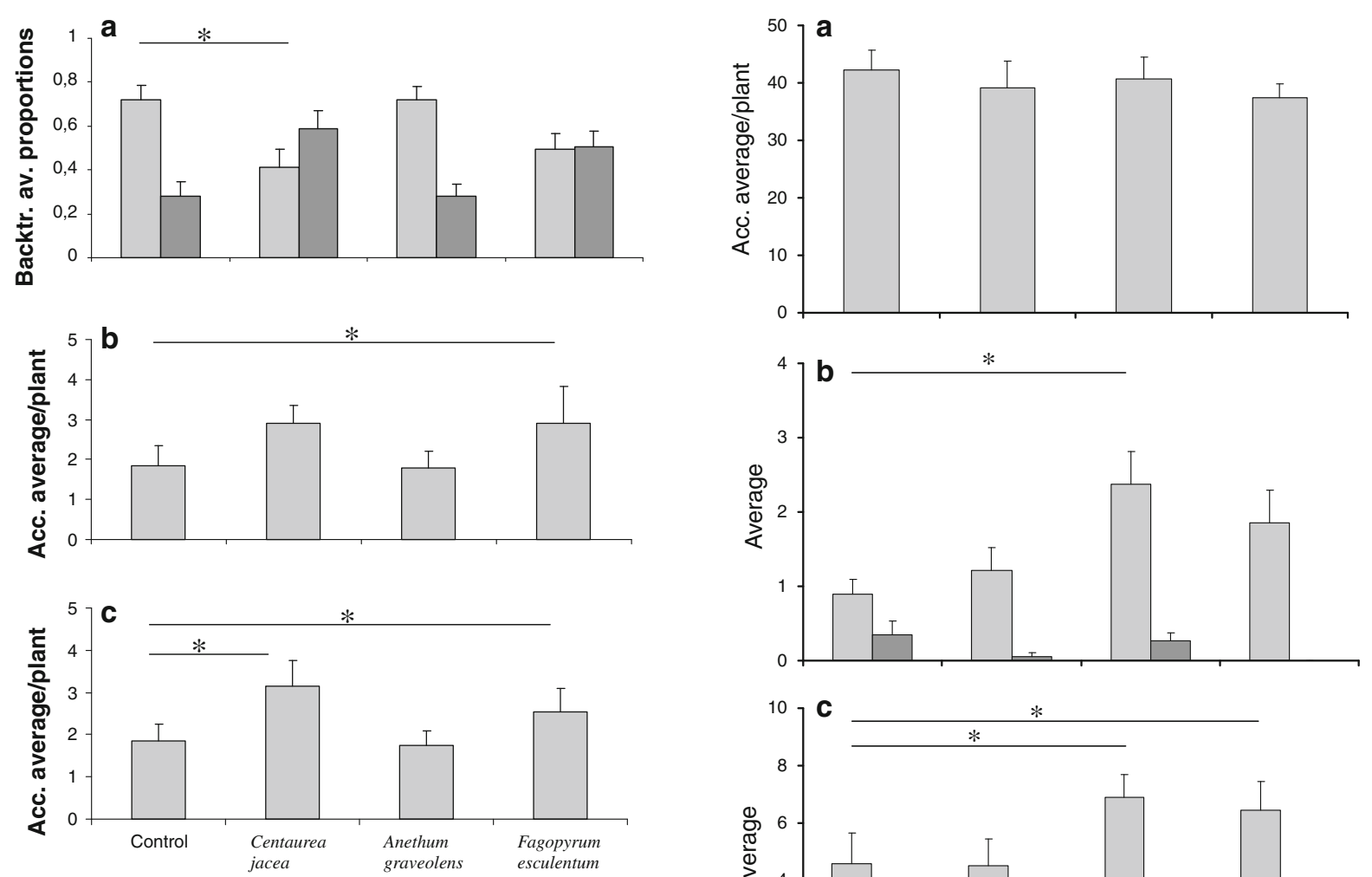

Fig. 2 Backtransformed average arcsine-root transformed proportions of a Pieris spp. adults in crop (light grey) and flower margins (dark grey), and average number per Brussels sprout plant of b Pieris rapae eggs and $\mathbf{c} P$. rapae larvae for the four different treatments. Data were pooled over years and locations. An asterisk indicates significant differences at $\alpha=0.05$ in the proportions of Pieris spp. adults and in the average number of Pieris rapae eggs and larvae between the control and any treatment. Error bars indicate SE values. Acc accumulated

mechanism responsible for the enhanced herbivore pressure.

When the Brassica crop was bordered by $C$. jacea, the proportion of adult $P$. rapae observed in the margins was significantly higher as compared to the margin of the control treatment planted with L. perenne. This finding fits well with our prediction that $C$. jacea is especially attractive to Pieris sp. Winkler et al. (2005a) found significantly higher numbers of Pieris sp. visiting C. jacea and Oregano vulgare in comparison to $F$. esculentum and five other flowering plants when using $3 \times 3 \mathrm{~m}$ single species plots.

For the pooled data over years there was a significant effect of $F$. esculentum on the number of

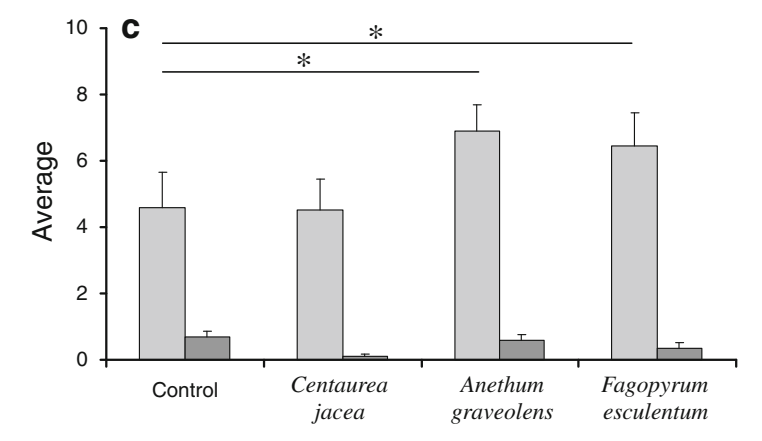

Fig. 3 Average number of a $P$. xylostella caterpillars per Brussels sprout plant for the four different treatments and average number of b Diadegma semiclausum females and c males in crop (light grey) and edges (dark grey). Data were pooled over years and locations. Significant differences in the crop at $\alpha=0.05$ between the control and any treatment are indicated by an asterisk. Error bars indicate SE values

$P$. rapae eggs. $C$. jacea had a significant effect on the number of $P$. rapae eggs in 2003 only. This may be explained by the fact that in 2002, C. jacea was newly established and started flowering four weeks later as compared to 2003 (see Fig. 1). The oviposition behaviour of $P$. rapae is characterized by laying eggs singly on plants, followed by a linear flight pattern during which the butterfly passes over many suitable hosts without laying eggs (Root and Kareiva 1984; Yamamura 1999). In our experiments $P$. rapae females may have left a plot after two to three ovipositions. This means that in large 
commercial fields the impact of a field margin with suitable flowers may be at least equally marked.

Unlike the clear results with $P$. rapae we did not see any significant impact of flower margins on P. xylostella. Even though all of the flowers tested extended $P$. xylostella longevity under laboratory conditions, neither adults nor larvae showed increased numbers in plots with flower margins, relative to the control. The relatively low numbers of $P$. xylostella adults collected in this study is probably due to the fact that this species is primarily active at dusk (Harcourt 1954). Using sticky traps, Bukovinszky et al. (2003) found that field margins dominated by flowering Sinapis alba, increased pest densities in adjacent fields. De Groot et al. (2005) found significantly more P. xylostella individuals on sticky traps in plots planted with Lobularia maritima than in Brussels sprout and S. alba plots. Both plant species, L. maritima and $S$. alba, are host plants for $P$. xylostella, which means that these effects need not have been food-mediated.

When host plants are abundant, $P$. xylostella does not fly far between ovipositions, but shows a strong arrestment response and stays on the plant or moves to directly neighbouring plants (Justus and Mitchell 1996; Bukovinszky et al. 2005). In contrast to P. rapae, $P$. xylostella lays more than one egg on a host plant. Food supply $(0.5 \mathrm{M}$ sucrose solution) increased longevity by a factor of 3 (Winkler et al. 2005b). Lifespan of $P$. xylostella was prolonged when given access to $C$. jacea, A. graveolens and $F$. esculentum under laboratory conditions (Winkler et al. 2009a). Previously we were able to demonstrate that $P$. xylostella exploits nectar sources under field conditions (Winkler et al., 2009b). The lack of significant differences among the treatments in this study leads us to conclude that food supply was not the limiting factor for the realized fecundity by $P$. xylostella. This assumption is supported by observations on the lifetime oviposition curve of P. xylostella. P. xylostella lays $90 \%$ of the total number of eggs within the first four days (Harcourt 1954; Cardona 1997). Under laboratory conditions, P. xylostella lives on average five days without food (Winkler et al. 2009a). As P. xylostella shows far less flight activity as compared to $P$. rapae, their energetic needs are likely relatively low. This may explain the limited impact of nectar availability in this species. In addition, $P$. xylostella might have utilized other food sources in the field like honeydew, produced by the cabbage aphid Brevicoryne brassicae or by the cabbage whitefly $A$. proletella. These species were observed in (very) low densities throughout the season in all of the four treatments.

We expected higher parasitoid numbers and, consequently, increased rates of parasitism in plots neighboured by $A$. graveolens and F. esculentum. Laboratory as well as semi-field experiments demonstrated the positive impact of $F$. esculentum and A. graveolens on the longevity of D. semiclausum, as well as a substantial impact of $F$. esculentum on fecundity of D. semiclausum (Wratten et al. 2003; Winkler et al. 2006).

We did indeed find significantly higher numbers of D. semiclausum males and females in Brussels sprout fields bordered by A. graveolens. F. esculentum borders significantly increased the number of male D. semiclausum individuals in Brussels sprout. For female $D$. semiclausum, numbers of individuals were higher, but not significantly. During sampling we observed high numbers of bees and bumble bees on F. esculentum. Lee and Heimpel (2003) suggest that competition between bees and parasitoids on F. esculentum may restrict nectar access to parasitoids. This might explain the fact that this plant species did not have an impact on parasitoids as strong as expected in our study.

Independent of the treatment, the sex ratio of the collected D. semiclausum was strongly male-biased. Under natural conditions the sex ratio is approximately 1:1. Bukovinszky (personal comm.) found about as many D. semiclausum females as males on sticky traps in cabbage fields. Differences in flight behaviour might account for our male-biased catches. Direct observations on individual wasps in the field confirmed that males tend to fly more and fly above the canopy, while females fly within the canopy, close to the plant, while searching for host larvae.

Regardless of the treatment, we found high rates of parasitism by D. semiclausum: $78 \%$ in 2002 and $67 \%$ in 2003. The density of $P$. xylostella larvae did not differ among the treatments. We did not find any effect of A. graveolens or F. esculentum field margins on rates of parasitism by $D$. semiclausum in adjacent Brussels sprout fields. Neither did we find an effect on sugar levels of field collected D. semiclausum (Winkler et al. 2009b). Similarly Lee and Heimpel (2005) found no consistent effect of F. esculentum on Diadegma insulare parasitism in cabbage plots. This 
is in stark contrast with earlier results of Winkler et al. (2006), where presence of buckwheat plants near cabbage plants dramatically increased lifespan and fecundity of D. semiclausum. The finding of equal rates of parasitism in the present study may be explained by the fact that D. semiclausum might have exploited alternative food sources like honeydew. Wäckers and Steppuhn (2003) could demonstrate honeydew consumption for Cotesia glomerata and Microplitis mediator collected in a cabbage field where the cabbage aphid B. brassicae and the cabbage whitefly Aleyrodes proletella were present.

The high migration capacity of D. semiclausum might have further diluted the effect of the different treatments. As alternative food sources were extremely rare in the studies by Lee et al. (2006), they suggest between-treatment dispersal of a least $67 \mathrm{~m}$ for D. insulare. Thompson (2002) suggests that D. semiclausum travels more than $400 \mathrm{~m}$ within $12 \mathrm{~h}$, with a net replacement distance of $55 \mathrm{~m}$. Lavandero et al. (2005) found that D. semiclausum can move $80 \mathrm{~m}$ within four days. For the brachonid wasp Dolichogenidea tasmanica Scarratt et al. (2008) could demonstrate migration up to $30 \mathrm{~m}$ at least. Thus, the isolation distance of $35 \mathrm{~m}$ between our plots might have been too small to prevent nectar-fed wasps from dispersing among the plots. Lavandero et al. (2005) used larger distances of $60 \mathrm{~m}$ between plots and could demonstrate differences in parasitism rates due to plantings of $F$. esculentum.

We could demonstrate that previously reported findings from laboratory experiments regarding impacts of floral resources on herbivores and their parasitoids extend in part to distribution patterns under field conditions. The result that the indiscriminate use of nectar plants in flowering field margins can enhance pest pressure provides a mechanism that may explain the instances in which increased plant biodiversity has been linked to higher levels of herbivory (Andow 1991; Bianchi et al. 2006). Our finding that the impact of floral resources is a function of insect- and flower-species underlines the importance of an informed selection of non-crop vegetation for the optimization of conservation biological control programmes or other ecosystem services.

Open Access This article is distributed under the terms of the Creative Commons Attribution Noncommercial License which permits any noncommercial use, distribution, and reproduction in any medium, provided the original author(s) and source are credited.

\section{References}

Andow DA (1991) Vegetational diversity and arthropod population response. Annu Rev Entomol 36:561-586

Baggen LR, Gurr GM (1998) The influence of food on Copidosoma koehleri (Hymenoptera: Encyrtidae), and the use of flowering plants as a habitat management tool to enhance biological control of potato moth, Phthorimaea opercullela (Lepidoptera: Gelechiidae). Biol Control 11:9-17

Bianchi FJ, Wäckers FL (2008) Effects of flower attractiveness and nectar availability in field margins on biological control by parasitoids. Biol Control 46:400-408

Bianchi FJ, Booij CJ, Tscharntke T (2006) Sustainable pest regulation in agricultural landscapes: a review on landscape composition, biodiversity and natural pest control. Proc Biol Sci 273:1715-1727

Bukovinszky T, Brewer MJ, Winkler K, Trefas H, Vet LEM, van Lenteren JC (2003) Effects of flowering field margins on flight activity of the diamondback moth (Plutella $x y$ lostella L.) and its parasitoids Diadegma spp., and observations on distance from field edge, and vertical position of traps. In: Integrated control in field vegetable crops, IOBC/WPRS Bulletin, pp 307-314

Bukovinszky T, Potting RPJ, Clough Y, van Lenteren JC, Vet LEM (2005) The role of pre- and post-alighting detection mechanisms in the responses to patch size by specialist herbivores. Oikos 109:435-446

Cardona EV (1997) Integrated pest management of the diamondback moth (Plutella xylostella L.) in cabbage in the Philippines: Biological control with the use of the parasitoid Diadegma semiclausum Hellen. In: Applied biological sciences: agriculture. University Gent, Gent, p 117

De Groot M, Winkler K, Potting R (2005) Testing the potential of White mustard (Sinapis alba) and Sweet alyssum (Lobularia maritima) as trap crops for the Diamondback moth Plutella xylostella. Proc Neth Entomol Soc Meet 16:117-123

Grossmueller DW, Lederhouse RC (1987) The role of nectar source distribution in habitat use and oviposition by the tiger swallowtail butterfly. J Lep Soc 41:159-165

Gurr GM, Wratten SD, Tylianakis J, Kean J, Keller M (2005) Providing plant foods for natural enemies in farming systems: balancing practicalities and theory. In: Wäckers FL, van Rijn PCJ, Bruin J (eds) Plant-provided food for carnivorous insects: a protective mutualism and its applications. Cambridge University Press, pp 326-347

Harcourt DG (1954) The biology and ecology of the diamondback moth, Plutella maculipennis, Curtis, in Eastern Ontario. PhD thesis, Cornell University, New York, p 107

Heimpel GE, Jervis MA (2005) Does floral nectar improve biological control by parasitoids? In: Wäckers FL, van Rijn PCJ, Bruin J (eds) Plant-provided food for carnivorous insects: a protective mutualism and its applications. Cambridge University Press, pp 267-304 
Idris AB, Grafius E (1995) Wildflowers as nectar sources for Diadegma insulare (Hymenoptera; Ichneumonidae), a parasitoid of diamondback moth (Lepidoptera: Yponomeutidae). Environ Entomol 24:1726-1735

Justus KA, Mitchell BK (1996) Oviposition site selection by the diamondback moth, Plutella xylostella (L.) (Lepidoptera: Plutellidae). J Insect Behav 9:887-898

Karban R (1997) Neighbourhood affects a plant's risk of herbivory and subsequent success. Ecol Entomol 22:433-439

Latheef MA, Irwin RD (1979) The effect of companionate planting of lepidopteran pests of cabbage. Can Entomol 111:863-864

Lavandero B, Wratten SD, Shishehbor P, Worner S (2005) Enhancing the effectiveness of the parasitoid Diadegma semiclausum (Helen): movement after use of nectar in the field. Biol Control 34:152-158

Lee JC, Heimpel GE (2003) Nectar availability and parasitoid sugar feeding. In: Proceedings 1st international symposium on biological control of arthropods, pp 220-225

Lee JC, Heimpel GE (2005) Impact of flowering buckwheat on lepidopteran cabbage pests and their parasitoids at two spacial scales. Biol Control 34:290-301

Lee JC, Heimpel GE (2008) Floral resources impact longevity and oviposition rate of a parasitoid in the field. $\mathrm{J}$ Anim Ecol 77:565-572

Lee JC, Andow DA, Heimpel GE (2006) Influence of floral resources on sugar feeding and nutrient dynamics of a parasitoid in the field. Ecol Entomol 31:470-480

McEwen PK, Liber H (1995) The effect of adult nutrition on the fecundity and longevity of the olive moth Prays oleae (Bern.). J Appl Entomol 119:291-294

Murphy DD (1983) Nectar sources as constraints on the distribution of egg masses by the checkerspot butterfly, $E u$ phydryas chalcedona (Lepidoptera: Nymphalidae). Environ Entomol 12:463-466

Murphy DD, Menniger MS, Ehrlich PR (1984) Nectar source distribution as a determinant of oviposition host species in Euphydryas chalcedona. Oecologia 62:269-271

Patt JM, Hamilton GC, Lashomb JH (1997) Impact of stripinsectary intercropping with flowers on conservation biological control of the colorado potato beetle. Adv Hort Sci 11:175-181

Romeis J, Städler E, Wäckers FL (2005) Nectar- and pollenfeeding by adult herbivorous insects. In: Wäckers FL, van Rijn PCJ, Bruin J (eds) Plant-provided food for carnivorous insects: a protective mutualism and its applications. Cambridge University Press, pp 178-219

Root RB, Kareiva PM (1984) The Search for resources by cabbage butterflies (Pieris rapae)_ecological consequences and adaptive significance of markovian movements in a patchy environment. Ecology 65:147-165

Scarratt SL, Wratten SD, Shishehbor P (2008) Measuring parasitoid movement from floral resources in a vineyard. Biol Control 46:107-113

Stephens MJ, France CM, Wratten SD, Frampton C (1998) Enhancing biological control of leafrollers (Lepidoptera: Tortricidae) by sowing buckwheat (Fagopyrum esculentum) in an orchard. Biocontrol Sci Technol 8:547-558

Takasu K, Lewis WJ (1994) Importance of adult food sources to host searching of the larval parasitoid Microplitis croceipes. Biol Control 5:25-30
Thompson L (2002) Foraging movements of Diadegma semiclausum, a parasitoid of diamondback moth (Plutella $x y$ lostella). Thesis, Department of Applied and Molecular Ecology, University of Adelaide, p 99

van Lenteren JC, Vianen AV, Gast HF, Kortenhoff A (1987) The parasite-host relationship between Encarsia formosa (Hym., Aphelinidae) and Trialeurodes vaporariorum (Hom., Aleyrodidae): XVI. Food effects on oogenesis, oviposition, life-span and fecundity of Encarsia formosa and other hymenopterous parasites. J Appl Entomol 103:69-84

Wäckers FL (1994) The effect of food deprivation on the innate visual and olfactory preferences in the parasitoid Cotesia rubecula. J Insect Physiol 40:641-649

Wäckers FL (2001) A comparison of nectar- and honeydew sugars with respect to their utilization by the hymenopteran parasitoid Cotesia glomerata. J Insect Physiol 47:1077-1084

Wäckers FL, Steppuhn A (2003) Characterizing nutritional state and food source use of parasitoids collected in fields with high and low nectar availability. IOBC/WPRS Bull 26:203-208

Wäckers FL, Romeis J, Van Rijn PCJ (2007) Nectar and pollen feeding by insect herbivores and implications for multitrophic interactions. Annu Rev Entomol 52:301-323

White AJ, Wratten SD, Berry NA, Weigmann U (1995) Habitat manipulation to enhance biological control of Brassica pests by hover flies (Diptera: Syrphidae). J Econ Entomol 88:1171-1176

Winkler K, Wäckers FL, Buitriago L, van Lenteren JC (2005a) Herbivores and their parasitoids show differences in abundance on eight different nectar producing plants. Proc Neth Entomol Soc Meet 16:125-130

Winkler K, Wäckers FL, Stingli A, van Lenteren JC (2005b) Plutella xylostella (diamondback moth) and its parasitoid Diadegma semiclausum show different gustatory and longevity responses to a range of nectar and honeydew sugars. Entomol Exp Appl 115:187-192

Winkler K, Wäckers FL, Bukovinszkine-Kiss G, van Lenteren JC (2006) Nectar resources are vital for Diadegma semiclausum fecundity under field conditions. Basic Appl Ecol 7:133-140

Winkler K, Wäckers FL, Kaufman LV, Larraz VG, van Lenteren JC (2009a) Nectar exploitation by herbivores and their parasitoids is a function of flower species and relative humidity. Biol Control 50:299-306

Winkler K, Wäckers FL, Pinto D (2009b) Nectar-providing plants enhance the energetic state of herbivores as well as their parasitoids under field conditions. Ecol Entomol 34:221-227

Wratten SD, Lavandero BI, Tylianakis J, Vattala D, Cigli T, Sedcole R (2003) Effects of flowers on parasitoid longevity and fecundity. NZ Plant Prot 56:239-245

Yamamura K (1999) Relation between plant density and arthropod density in cabbage. Res Popul Ecol 41:177-182

Zhao JZ, Ayers GS, Grafius EJ, Stehr FW (1992) Effects of neighbouring nectar-producing plants on populations of pest Lepidoptera and their parasitoids in broccoli plantings. Great Lakes Entomol 25:253-258

Zoebelein G (1955) Der Honigtau als Nahrung der Insekten. $\mathrm{Z}$ Angew Entomol 38:369-416 